\title{
Коэффициенты тензочувствительности датчиков механических напряжений на разных физических принципах
}

\author{
А.Г. Паулиш ${ }^{1,2)}$, П. С. Загубисало ${ }^{1)}$ \\ ${ }^{1}$ Новосибирский филиал Института физики полупроводников им. А. В. Ржанова СО РАН \\ «Конструкторско-технологический институт прикладной микроэлектроники», \\ 630090, г. Новосибирск, просп. Академика Лаврентьева, 2/1 \\ ${ }^{2}$ Новосибирский государственный технический университет, 630073, г. Новосибирск, \\ просп. К. Маркса, 20 \\ тел:+7 (383) 316-5910, факс:+7 (383) 330-9106, эл.nочта: paulish63@ngs.ru
}

DOI 10.34077/RCSP2019-173

Измерение механических напряжений является основным экспериментальным методом изучения напряженных состояний в различных конструкциях. Сегодня наиболее широко используемыми устройствами для измерения механических напряжений являются датчики, основанные на тензорезистивном и пьезоэлектрическом эффектах. Также используются волоконно-оптические датчики. При описании чувствительности разных датчиков используют различные величины, что затрудняет сравнение их между собой. Например, для пьезоэлектрических датчиков приводится пьезоэлектрический модуль с размерностью Кл/Н, в то время как тензорезисторные датчики характеризуются безразмерной величиной - коэффициентом тензочувствительности: отношение относительного изменения измеряемой величины к относительному удлинению. В научной литературе отсутствуют данные о сравнительном анализе тензочувствительности применяемых в промышленности датчиков деформации на разных физических принципах, что затрудняет объективную оценку их преимуществ и недостатков.

Целью работы является определение коэффициента тензочувствительности пьезооптического датчика механических напряжений, выяснение его зависимости от конструктивного исполнения датчика и сравнение с коэффициентами тензочувствительности датчиков на основе тензорезистивного, пьезоэлектрического эффектов, а также с волоконно-оптическими датчиками.

Проведен сравнительный анализ коэффициентов тензочувствительности и других параметров тензорезисторных, пьезоэлектрических, оптоволоконных и пьезооптических датчиков деформации. Показано, что коэффициент тензочувствительности, определяемый как отношение относительного изменения измеряемой величины к относительному удлинению, не зависит от конструкции датчика для тензорезисторных, пьезоэлектрических и волоконно-оптических датчиков деформации. Наоборот, для пьезооптических датчиков коэффициент тензочувствительности зависит от конструкции датчика и может быть улучшен за счёт оптимизации его элементов. Коэффициенты тензочувствительности тензорезисторных и волоконно-оптических датчиков на три порядка ниже, чем для пьезооптических датчиков. Показано, что, несмотря на высокие значения пьезоэлектрических модулей новых пьезоматериалов, их коэффициенты тензочувсвительности находятся на уровне тензорезисторных датчиков и на два-три порядка уступают коэффициенту для пьезооптических датчиков.

В работе методом численного моделирования показано, что зависимости чувствительности к силе и чувствительности к деформации от формы фотоупругого элемента для пьезооптических датчиков ведут себя по-разному, что необходимо учитывать при практическом применении таких датчиков. В работе предложено использование эффективного модуля упругости фотоупругого элемента, зависящего от его конструкции, для описания тензочувствительности пьезооптического датчика деформации. В итоге, задачей конструирования формы ФЭ и способа передачи на него внешней силы является получение максимально возможного эффективного модуля упругости.

Коэффициент тензочувствительности пьезооптического датчика на кварцевом стекле, полученный численным моделированием напряжений и деформаций в ФЭ, подтверждает экспериментально полученный результат и на два-три порядка превышает коэффициенты тензочувствительности датчиков, основанных на других физических принципах. Пьезооптический датчик не содержит материалов, чьи свойства меняются со временем, поэтому в нём не должно быть гистерезиса и деградации параметров со временем. Таким образом, пьезооптические преобразователи являются наиболее перспективными для создания надежных малогабаритных высокочувствительных датчиков механических напряжений. 